\title{
SALMONELLA MENINGITIS
}

\author{
BY \\ KENNETH C. WATSON \\ From the Department of Pathology, University of Natal, and King Edward VIII Hospital, Durban, South Africa
}

(RECEIVED FOR PUBLICATION AUgUST 19, 1957)

Meningitis due to organisms of the salmonella group is a relatively uncommon condition but is of importance because of the very high mortality rate which has been recorded. The first case of meningitis due to this cause was reported by Ghon (1908) and was due to Salmonella paratyphi $B$. The literature since that time has been reviewed by several authors including Bahrenburg and Ecker (1937) who reported 34 cases, Ramón Guerra, Peluffo, Laguarda and Aleppo (1939), Henderson (1948) and Beene, Hansen and Fulton (1951). Henderson (1948) has produced the most comprehensive review of the subject and quotes 144 cases, including three of his own, due to $S$. panama, $S$. newport, and $S$. typhi-murium respectively. The report by Beene et al. (1951) includes a further 87 cases not referred to by Henderson. These include 17 cases due to $S$. typhi which Henderson specifically excluded from his review. These authors also include a case of their own due to $S$. montevideo, the first recorded case due to this organism.

Three epidemic outbreaks in newborn infants have been reported. Guthrie and Montgomery (1939) discuss 12 cases due to $S$. enteritidis. In each one there was diarrhoea with vomiting, convulsions, coma, and a fatal termination. Post-mortem examination showed a purulent meningitis associated with catarrhal enteritis. Curbelo and Martinez Cruz (1941) reported 21 cases in newborn infants in an explosive-type outbreak in Cuba. Here the causative organism was $S$. havana and again there was a fatal outcome in each patient. High and Spaulding (1946) recorded a further outbreak involving ten infants, due to $S$.panama, again with a $100 \%$ fatality rate.

During the past 18 months four cases of salmonella meningitis have been encountered in this hospital. Two of these have been due to species of salmonella not previously reported as having been found in the cerebrospinal fluid, namely, S. johannesburg and $S$. heidelberg.

\section{Reports of Cases}

Case 1. M.P., a female Bantu infant aged 11 months, was admitted to hospital with a history of loss of appetite and general malaise. The child had recently had an attack of whooping cough complicated by bronchopneumonia and had apparently not fully recovered. No further details were obtainable from the relatives.

On examination, the child appeared listless and apathetic. The temperature was $103.0^{\circ} \mathrm{F}$. and the pulse rate 130 per minute. The skin showed some signs of dehydration but the anterior fontanelle was tense and bulging. There was marked neck stiffness and Kernig's sign was positive. The deep reflexes were equal and brisk. The ocular fundi appeared normal. Examination of other systems was essentially negative. Shortly after admission the child had a number of generalized convulsions.

Lumbar puncture showed a turbid fluid under greatly increased pressure. Queckenstedt's test gave a normal response. The fluid had the following composition: protein, $200 \mathrm{mg}$. \%; sugar, $10 \mathrm{mg}$. \%; globulin (Pandy's test), greatly increased; chlorides, $670 \mathrm{mg}$. \%; lymphocytes, 120 per c.mm.; polymorphonuclear leucocytes, 620 per c.mm. A Gram stained film of the fluid showed the presence of many Gram negative bacilli. Culture of the fluid resulted in the isolation of an organism of the salmonella group. Further examination of it showed its antigenic structure to be IV, V, XII : r-1, 2, 3, which is that of $S$. heidelberg. Sensitivity testing in vitro by the dried disc method showed the organism to be sensitive to chloramphenicol, streptomycin and the tetracycline group of antibiotics.

Treatment was begun on the day of admission with $0.25 \mathrm{~g}$. of streptomycin intramuscularly followed by $0.25 \mathrm{~g}$. twice daily. Chloramphenicol, $125 \mathrm{mg}$., was also given intramuscularly followed by $125 \mathrm{mg}$. every six hours. During the subsequent ten days there was little change in the clinical state. The cerebrospinal fluid four days after admission was sterile. In view of the poor response, chloramphenicol was discontinued after ten days and tetracycline, $125 \mathrm{mg}$. intramuscularly every six hours, was given instead. Again there was no improvement under this regime and culture of the cerebrospinal fluid in the third week of illness gave rise to a heavy growth of $S$. heidelberg. There was a gradual deteriora- 
tion in the infant's condition and death took place one month after admission. Permission for necropsy was refused.

Case 2. M.D., a male Bantu infant aged 5 months, was admitted with a history of diarrhoea of one month's duration. No further clinical history was obtained. The child was in a state of coma with a temperature of $102 \cdot 6^{\circ} \mathrm{F}$. and a pulse rate of 126 per minute. There was a pronounced squint and marked neck stiffness with a positive Kernig's sign. Examination of the lungs showed signs suggestive of bronchopneumonia. Examination of other systems was negative.

Lumbar puncture on admission showed a turbid fluid under increased pressure. The fluid had the following composition: protein, $500 \mathrm{mg}$. \%; chlorides, $670 \mathrm{mg}$. \%; sugar, $47 \mathrm{mg}$. \%; globulin, marked excess; polymorphonuclear leucocytes, 800 per c.mm. and lymphocytes, 120 per c.mm. Gram stained films showed large numbers of Gram negative bacilli. Culture of the fluid resulted in the isolation of an organism of the salmonella group. Subsequent antigenic analysis showed its structure to be as follows: I, IX, XII : g, p-, which is that of $S$. dublin.

The child died some 20 minutes after admission. Necropsy examination showed an extensive purulent meningitis. There was a moderate degree of fatty change in the liver and areas of bronchopneumonic consolidation were present in both lungs.

Case 3. S.J., a 4-month-old female Bantu infant, was admitted to hospital with a two weeks' history of diarrhoea accompanied by vomiting. No further details were available from the relatives apart from the fact that she had been in hospital one month previously with a similar complaint.

The child was in a moribund state. The temperature was $103 \cdot 2^{\circ} \mathrm{F}$. and pulse rate 126 per minute. The respirations were rapid and coarse crepitations were present in the right mid-zone. The anterior fontanelle was tense and bulging. The eyes were deviated to the right side and there was a marked degree of neck retraction and some degree of opisthotonos. Kernig's sign was positive. Both upper and lower limbs were very rigid. The deep reflexes were brisk. The pupils were equal, central and reacted to light. The spleen was palpable one finger breadth below the costal margin. Examination of other systems was negative.

Lumbar puncture was performed but only a small quantity of fluid was obtained by aspiration. Queckenstedt's test indicated the presence of a block. Examination of the fluid revealed a large number of polymorphonuclear leucocytes and numerous Gram negative bacilli. There was a marked excess of globulin but insufficient fluid was available for further biochemical investigation. Culture of the fluid resulted in the growth of an organism which on further investigation was found to be a salmonella with the following antigenic structure : $I, X L: b-e, n, x$. This is the antigenic formula of $S$. johannesburg. The organism was sensitive in vitro to chloramphenicol, streptomycin and the tetracycline group of antibiotics.
On admission the child was given 500,000 units of penicillin intramuscularly. Following the report of a probable salmonella infection chloramphenicol therapy was begun the next day with $250 \mathrm{mg}$. intramuscularly and then $250 \mathrm{mg}$. every six hours. Streptomycin, $0.5 \mathrm{~g}$., was also given intramuscularly. The child's condition was critical, however, and death occurred the following day. Permission for necropsy was refused.

Case 4. T.X., a 3-year-old female Bantu child, was admitted to hospital with a history of having had a convulsion during sleep a few hours earlier. The convulsion had involved all limbs equally and since then the child had been in a state of coma. Before the onset of the convulsion the child had apparently been quite well. No previous history of convulsions was admitted and the past medical history was negative.

The child was in coma with a temperature of $105.0^{\circ} \mathrm{F}$. and pulse rate of 118 per minute. She was having almost continuous convulsive movements involving all four limbs but especially marked on the left side. The head was rotated to the left. The pupils were dilated and did not react to light. There was no evidence of neck retraction and Kernig's sign was negative. The deep reflexes on both sides were brisk and the plantar responses were flexor in type. There was bilateral purulent conjunctivitis. Examination of other systems was negative.

Lumbar puncture revealed a purulent fluid under increased pressure containing: protein, $500 \mathrm{mg}$. $\%$; chloride, $700 \mathrm{mg}$. \%; sugar, $70 \mathrm{mg}$. \%; globulin, marked excess; polymorphonuclear leucocytes, large numbers. Gram stained films showed many Gram negative bacilli. Culture of the fluid resulted in the isolation of an organism giving the biochemical reactions of a salmonella. This organism, however, was in a rough phase and all attempts to obtain the smooth state were unsuccessful. Consequently the antigenic formula is in doubt. The organism was sensitive in vitro to chloramphenicol, streptomycin, and the tetracycline group of antibiotics.

Chloramphenicol, $250 \mathrm{mg}$., was given intramuscularly followed by a similar dose every six hours. During the following few days the child developed marked signs of meningeal irritation with neck retraction and a positive Kernig's sign. There was little improvement in the clinical state for a period of some three weeks during which time she remained pyrexial. The causative organism was still present in the cerebrospinal fluid one week after admission but the fluid became sterile on the tenth day. After three weeks there was a gradual slow recovery complicated at one stage by the development of measles. The child was discharged three months after admission apparently cured.

\section{Discussion}

Salmonella organisms infecting the leptomeninges give rise to an acute purulent meningitis. In infants the clinical course of illness is often rapid and is more often associated with diarrhoea and lesions in the gastro-intestinal tract than is the case with 
older children and adults. However, just as in other forms of meningitis, the classical signs of meningeal irritation may be lacking in the infant and thus render the diagnosis more difficult. This was the case in our fourth patient where on admission there was nothing to indicate the presence of acute meningitis.

Age Incidence of Salmonella Meningitis. The age incidence of salmonella meningitis shows that there is a striking tendency for the very young to be affected. Table 1 shows the age distribution in 138 patients. This includes some of the patients reported by Henderson (1948) together with subsequent reports where the age group was available and including the four cases reported here.

TABLE 1

AGE INCIDENCE OF 138 CASES OF SALMONELLA MENINGITIS

\begin{tabular}{c|c|c|c|c|c}
\hline & \multicolumn{5}{|c}{ Age Groups } \\
\cline { 2 - 6 } $\begin{array}{c}\text { Number } \\
\text { of Cases }\end{array}$ & $\begin{array}{c}\text { New- } \\
\text { born }\end{array}$ & $\begin{array}{c}\text { Less than } \\
\text { 3 Months }\end{array}$ & $\begin{array}{c}3 / 12-1 \\
\text { Year }\end{array}$ & $\begin{array}{c}1-15 \\
\text { Years }\end{array}$ & $\begin{array}{c}15+ \\
\text { Years }\end{array}$ \\
\hline 138 & 55 & 31 & 26 & 14 & 12 \\
\hline
\end{tabular}

The above figures show that 112 of the 138 cases $(81 \%)$ occurred in infants under the age of 1 year and all but 12 occurred in children under the age of 15. The reason for this age distribution is not clearly apparent since the pathogenesis of salmonella meningitis is incompletely understood, but it is largely in keeping with certain other forms of meningitis such as the tuberculous and influenzal varieties. However, infection by salmonella organisms, where the clinical manifestations are confined to the gastro-intestinal tract, does not appear to be more common in children than in adults. It seems probable that the organism is carried to the meninges via the blood stream and it has been suggested that the high rate in infants is due to the preceding birth trauma rendering the tissues more susceptible to infection. This may be a factor in certain cases such as that reported by Neter (1944) where meningitis developed in a child aged three years who had had hydrocephalus since birth. Such a theory, however, does not explain the occurrence of outbreaks amongst newborn infants. In these it may be that certain inherent characteristics of the organisms themselves may be concerned in the localization in the meninges. It has also been suggested that salmonella infections of the meninges may follow other types of infection of the central nervous system due to a lowering of the local tissue resistance. In the 144 cases reviewed by Henderson
(1948) five followed an attack of meningococcal meningitis and two others occurred during the course of treatment of syphilitic infections of the central nervous system. This hypothesis of decreased tissue resistance is one that is extremely difficult to prove or disprove. It is one which has been supported by Zinsser, Enders and Fothergill (1939) but it has lost much of its popularity in recent years. Neter (1944) has suggested that salmonella bacteraemia and meningitis may follow other types of infection such as otitis media, pyelitis and malaria. In our Case 1 the onset was preceded by an attack of whooping cough. It has also been suggested that the gastro-intestinal tract of the infant is more permeable to bacteria than that of the adult but again no satisfactory support for this hypothesis is available. One important factor is probably the well-known inability of the infant to produce a satisfactory antibody. Consequently, organisms gaining access to the blood stream are presumably in a more favourable position to reach the meninges and cause infection than in the adult where antibody formation is better.

Incidence of Various Salmonella Species. Table 2 shows the distribution of 151 salmonella species isolated from the cerebrospinal fluid and includes the four cases reported here in addition to those discussed by Henderson (1948). In addition to those shown in Table 2 the following species have been reported in isolated examples in the literature: $S$. bovis-morbificans, $S$. bredeney, $S$. manhattan, $S$. paratyphi $C, S$. blegdam, $S$. montevideo and S. dublin.

TABLE 2

SALMONELLA SPECIES IN 151 CASES OF SALMONELLA MENINGITIS

\begin{tabular}{l|r}
\hline Salmonella Species & Number of Cases \\
\hline S. paratyphi $B$ & 22 \\
S. paratyphi $A$ & 7 \\
S. enteritidis & 45 \\
S. cholerae-suis & 8 \\
S. typhi-murium & 13 \\
S. panama & 17 \\
S. havana & 21 \\
S. london & 1 \\
S. eastbourne & 1 \\
S. oranienburg & 1 \\
S. newport & 2 \\
S. anatum & 1 \\
S. derby & 1 \\
S. bareilly & 1 \\
S. loma-linda & 1 \\
S. new-brunswick & 1 \\
S. johannesburg & 1 \\
S. heidelberg & 1 \\
S. dublin & 1 \\
Undetermined & 5 \\
\end{tabular}

We have not included cases of meningitis due to $S$. typhi in this discussion. Although typhoid fever 
is extremely common in this part of the world, where we have had experience of some 400 cases in the past few years, we have not yet seen a case of true typhoid meningitis. Many patients with typhoid fever present with signs of meningeal irritation but the cerebrospinal fluid is usually normal or shows only a very slight increase in the number of cells.

The distribution of salmonella types in Table 2 is probably not altogether accurate in certain respects. Up to 1935 only four salmonella species had been reported from the cerebrospinal fluid, namely, $S$. paratyphi $B, S$. enteritidis, $S$. paratyphi $A$ and $S$. cholerae-suis. Lack of knowledge concerning the antigenic structure of the salmonella group would explain this failure to recognize other types. The increasing number of reports of salmonella species in the cerebrospinal fluid not previously identified makes it probable that any salmonella species, including many which are primarily pathogenic to animals, may localize in the meninges and cause meningitis.

Prognosis in Salmonella Meningitis. The death rate from this condition is high and particularly so in infants as compared with older children and adults. The introduction of broad spectrum antibiotics may materially alter the death rate in the future but so far experience with this form of treatment has been restricted by the small number of cases available. The incidence of sequelae is uncertain but is probably the same as that found in other forms of acute purulent meningitis. Table 3 below shows the number of deaths in relation to age group in a series of 143 cases where the age was known.

TABLE 3

NO. OF DEATHS RELATED TO AGE IN 143 CASES OF SALMONELLA MENINGITIS

\begin{tabular}{|c|c|c|c|c|}
\hline Age & & $\begin{array}{l}\text { Number } \\
\text { of Cases }\end{array}$ & $\begin{array}{l}\text { Number } \\
\text { of Deaths }\end{array}$ & $\begin{array}{c}\text { Percentage } \\
\text { Died }\end{array}$ \\
\hline $\begin{array}{l}\text { Newborn-30 days } \\
30-90 \text { days } \\
90 \text { days }-1 \text { year } \\
1-15 \text { years } \\
15 \text { + years .. }\end{array}$ & $\begin{array}{ll} & \ldots \\
\cdots & \cdots \\
\cdots & \cdots \\
\cdots & \cdots\end{array}$ & $\begin{array}{l}67 \\
20 \\
26 \\
18 \\
12\end{array}$ & $\begin{array}{r}63 \\
17 \\
23 \\
12 \\
9\end{array}$ & $\begin{array}{l}94 \cdot 0 \\
85 \cdot 0 \\
88 \cdot 4 \\
66 \cdot 6 \\
75 \cdot 0\end{array}$ \\
\hline
\end{tabular}

The figures in certain of the age groups are too small to be significant statistically but if we consider the number of deaths in children over and under one year it will be seen that there were 21 deaths in 30 cases $(70 \%)$ in the former group and 103 deaths in 113 cases $(91 \%)$ in the latter age group. If we subject these results to analysis by the $\chi^{2}$ test the probability (P) value for $\chi^{2}$ is greater than 3.84 which indicates a significance difference between the death rates at the $5 \%$ level.

In addition to the association of deaths with age groups, the number of deaths in relation to the type of salmonella involved is of interest. Table 4 shows the number of deaths in 133 cases due to seven different salmonella species.

TABLE 4

NO. OF DEATHS RELATED TO SALMONELLA SPECIES IN 133 CASES OF SALMONELLA MENINGITIS

\begin{tabular}{|c|c|c|c|}
\hline Salmonella Species & $\begin{array}{l}\text { Number } \\
\text { of Cases }\end{array}$ & $\begin{array}{l}\text { Number } \\
\text { of Deaths }\end{array}$ & $\begin{array}{c}\text { Percentage } \\
\text { Died }\end{array}$ \\
\hline $\begin{array}{l}\text { S. paratyphi } B \\
\text { S. paratyphi A } \\
\text { S. enteritidis } \\
\text { S. cholerae-suis } \\
\text { S. typhi-murium } \\
\text { S. panama } \quad \ldots \\
\text { S. havana } \quad .\end{array}$ & $\begin{array}{r}22 \\
7 \\
45 \\
8 \\
13 \\
17 \\
21\end{array}$ & $\begin{array}{r}13 \\
5 \\
45 \\
6 \\
13 \\
14 \\
21\end{array}$ & $\begin{array}{r}59 \cdot 0 \\
71 \cdot 4 \\
100 \cdot 0 \\
75 \cdot 0 \\
100 \cdot 0 \\
82 \cdot 3 \\
100 \cdot 0\end{array}$ \\
\hline
\end{tabular}

All the cases of $S$. enteritidis, $S$. typhi-murium and $S$. havana infection proved fatal whereas as high a recovery rate as $41 \%$ is recorded in the 22 cases of $S$. paratyphi $B$ infection. This finding does not seem to be related to age distribution since the number of cases in children under one year, due to $S$. enteritidis, is not statistically greater than those due to $S$. paratyphi $B$. Table 5 shows the relative age distribution of these two types of infection. It would appear that not all salmonella species have the same effect on the host though what factors may be responsible for the greater pathogenicity of some types as compared with others are at present unknown.

TABLE 5

DISTRIBUTION OF $S$. PARATYPHI B AND $S$. ENTERITIDIS WITH RESPECT TO AGE

\begin{tabular}{c|c|c|c|c|c|c}
\hline \multirow{2}{*}{ Organism } & \multicolumn{4}{|c|}{ Age Groups } & \\
\cline { 2 - 6 } & $\begin{array}{c}\text { Newborn- } \\
\text { 30 Days }\end{array}$ & $\begin{array}{c}30-90 \\
\text { Days }\end{array}$ & $\begin{array}{c}\text { 90 Days } \\
-1 \text { Year }\end{array}$ & $\begin{array}{c}1-15 \\
\text { Years }\end{array}$ & $\begin{array}{c}15+ \\
\text { Years }\end{array}$ & Total \\
\hline $\begin{array}{l}\text { S. paratyphi } B \\
\text { S. enteritidis .. }\end{array}$ & 6 & 6 & 3 & 3 & 3 & 21 \\
\hline
\end{tabular}

Treatment of salmonella meningitis is at present unsatisfactory. Following the introduction of sulphonamides a number of cures were reported and recovery has also been attributed to the effect of streptomycin (Pearlman and Gordon, 1949). Padnos and Goldin (1951) also reported recovery in a case due to $S$. bareilly which was treated with intravenous aureomycin. Most salmonella strains are sensitive in vitro to the tetracycline drugs and they reach the cerebrospinal fluid in adequate amounts. It remains to be seen, however, whether they will effect a reduction in the mortality rate from this disease.

\section{Summary}

Four cases of meningitis due to salmonella infections are reported. Two of these were due to 
salmonella strains not previously isolated from the cerebrospinal fluid, namely $S$. johannesburg and $S$. heidelberg.

Salmonella infections of the meninges occur most commonly in infants in whom there is a higher death rate than in adults or older children. Prognosis may depend on the type of salmonella responsible for the infection as well as the age group.

I wish to thank Dr. P. Klenerman, Paediatrician to King Edward VIII Hospital, for permission to quote from the case notes of the patients in her charge.

\section{REFERENCES}

Bahrenburg, J. H. and Ecker, E. E. (1937). J. infect. Dis., 60, 81. Beene, M. L., Hansen, A. E. and Fulton, M. (1951). Amer. J. Dis. Child. 82567.

Curbelo, A. and Martinez Cruz, J. A. (1941). Arch. Méd.Inf., 10, 170.

Ghon. (1908). Bericht über den XIV Internationalen Kongress für Hygiene und Demographie. Berlin, 1907, Vol. 4, p. 21 .

Guthrie, K. J. and Montgomery, G. L. (1939). J. Path. Bact., 49, 393.

Henderson, L. L. (1948). Amer. J. Dis. Child., 75, 351.

High, R. H. and Spaulding, E. H. (1946). Amer. J. Dis. Child., 72,181 .

Neter, E. R. (1944). Arch. intern. Med. 73, 425.

Padnos, E. and Goldin, M. (1951). J. Pediat., 38, 85.

Pearlman, L. N. and Gordon, A. S. P. (1949). Canad. med. Ass. J., 60, 483 .

Ramón Guerra, A., Peluffo, E., Laguarda, M. and Aleppo, P. L. (1939). Arch. Pediat. Urug., 10, 669.

Zinsser, H., Enders, J. F. and Fothergill, L. D. (1939). Immunity Principles and Application in Medicine and Public Health. New York. 